\title{
Methane and climate change
}

\author{
M. J. ULYATT ${ }^{1}$, H. CLARK ${ }^{2}$ and D K. R. LASSEY ${ }^{3}$ \\ ${ }^{1} 181$ Omokoroa Road, RD2 Tauranga \\ ${ }^{2}$ AgResearch Grasslands, Private Bag 11008, Palmerston North \\ ${ }^{3}$ National Institute of Water and Atmospheric Research Limited, PO Box 14-901, Wellington \\ mwu@paradise.net.nz
}

\begin{abstract}
The New Zealand government has indicated that it will ratify the Kyoto Protocol, which means that legally binding targets will be set for reducing greenhouse gas (GHG) emissions. In "preferred" policies to achieve these targets, the agricultural sector will not be taxed directly but is expected to contribute to research leading to methane mitigation. A wide range of possibilities other than reducing livestock numbers exist for lowering livestock methane emissions: increasing the efficiency of animal production, exploiting betweenanimal variation; anti-methanogenic feed additives; dietary manipulation, including pasture composition modification; immunisation; and, manipulation of the rumen microbial ecosystem. Reduction in methane will not only have global environmental benefits, but also, as methane represents a loss of about $6 \%$ of an animal's energy intake, any reduction should be reflected in increased animal productivity per unit of intake. It should be possible to deliver a win/win situation with respect to methane reduction and increased productivity. Keywords: climate change, inventory, methane, mitigation, ruminants
\end{abstract}

\section{Introduction}

The United Nations Framework Convention on Climate Change (UNFCC) defines climate change as "a change in climate which is attributed directly or indirectly to human activity that alters the composition of the global atmosphere and which is in addition to natural climate variability". All agricultural activities come under this definition. The balance of scientific opinion is that the earth is undergoing warming and that there is discernable human influence (IPCC 2001). The evidence is indirect and comes from thermometer records over the past 140 years, satellite and weather balloon records, analysis of tree growth rings, coral and ice core data, rising sea levels, retreating glaciers and ice cover, and historical records. The global average surface temperature has increased by about $0.6^{\circ} \mathrm{C}$ during the $20^{\text {th }}$ century, with the 1990 s the warmest decade and 1998 the warmest year since instrumental records began in 1861 (IPCC 2001). Increases in atmospheric $\mathrm{CO}_{2}$ and $\mathrm{CH}_{4}$ concentrations are highly correlated with the rise in temperature over the past 150 years. These increases coincide with the increase in industrialisation and in agricultural activity, widespread changes in land use such as deforestation and the use of fossil fuels as an energy source. These are the two major greenhouse gases (GHG): gases that are largely responsible for heating in the atmosphere by absorbing infra-red radiation emitted from the earth's surface and preventing it from escaping into space. The inference is, therefore, that the increase in GHGs is responsible for the global warming.

Methane is particularly important to New Zealand. New Zealand's per capita methane emission is approximately 6 times the OECD average and 10 times the world average. In 2000, on a $\mathrm{CO}_{2}$ equivalent basis, methane was responsible for $43 \%$ of our $\mathrm{GHG}$ emissions, compared to $40 \%$ for $\mathrm{CO}_{2}$ and $16 \%$ for $\mathrm{N}_{2} \mathrm{O}$ (New Zealand Climate Change Project, 2002). This GHG profile is unusual among developed countries. This is because our methane emissions come predominantly from enteric fermentation in the rumen of ruminant livestock and we have relatively high livestock and low human populations. Of the $1.5 \mathrm{Tg}$ of methane emitted per year by New Zealand ruminants in 1990, it was been calculated that sheep produced $58 \%$, beef cattle $21 \%$, dairy cattle $18 \%$, deer $2 \%$ and goats $1 \%$ (Ulyatt et al. 1991). There is also some evidence that young animals emit less methane per unit of feed consumed than mature animals (M. J. Ulyatt unpublished)

\section{Political considerations}

Most countries in the world recognise that there is a climate change problem and there has been considerable political activity in recent years resulting in major international agreements. In 1992 the UNFCCC was adopted at the Earth Summit held in Rio de Janeiro and as a result developed nations agreed to voluntarily try and return to 1990 GHG emission levels by 2000 and to compile annual national GHG inventories. A further, stronger, international agreement, the Kyoto Protocol (KP) to the UNFCCC, was adopted in 1997 in which targets and timetables were set for cutting developed country emissions. New Zealand's target was zero change between 1990 and the commitment period of the average of 2008-2012. At the time of writing (May 
2002) the New Zealand government has signalled that it intends to ratify the KP this year. The provisions of the $\mathrm{KP}$ will become legally binding once it is ratified by 55 parties to the UNFCCC including developed countries accounting for $55 \%$ of emissions. The New Zealand government released its preferred policy package for the domestic implementation of the Protocol in April 2002. This divides the economy into four groups: a small "competitiveness at risk" group that has high energy use will be fully shielded from any emissions charge; a "general energy users" group, including the energy and transport sector, most businesses and households, will face an emissions tax; agriculture would not be charged directly, instead the industry would be expected to fund research to mitigate methane emission; and, an "other" group, which includes methane from landfills and synthetic trace gases, would be managed by a mixture of regulation and industry agreement. Sink credits for activities such as forestry would be retained by the government and any revenue recycled back into the economy. These preferred options will be discussed with industry in mid 2002 and a final policy package determined by August 2002.

\section{Inventory}

In order to meet national and international reporting requirements, to develop policy and to develop mitigation strategies, it is essential that New Zealand develops an accurate and detailed inventory of ruminant methane emission. This has been difficult technically because most methane is emitted from freely grazing animals, so until recently the inventory has been calculated using a mathematical model (Ulyatt et al. 1991). Recently the sulphur hexafluoride $\left(\mathrm{SF}_{6}\right)$ tracer technique has been used to obtain measurements of methane emission from grazing animals (eg, Lassey et al. 1997). Work is currently underway to incorporate these new data into the national methane inventory methodology. This work is in its early stages but indicates that the mathematical model used previously tended to over estimate methane emissions per unit of feed intake. The further incorporation into the inventory of better data on animal productivity changes over time suggests that the emissions from New Zealand livestock have increased since 1990 (Clark 2001).

\section{Methane mitigation possibilities and strategies}

A wide range of possibilities exist for lowering livestock methane emissions, other than reducing livestock numbers: increasing the efficiency of animal production, dietary manipulation, exploiting betweenanimal variation; anti-methanogenic feed additives; immunisation; and, manipulation of the rumen microbial ecosystem all have potential.

\section{Increasing the efficiency of livestock production}

Improving the efficiency of ruminant animal performance will generally lead to a reduction of methane emitted per unit of animal product. There are two aspects of this:

(1) Genetic improvement of the animals themselves, to achieve more production per unit of feed intake, as has been achieved with pigs and poultry.

(2) Dietary manipulation. Dietary manipulation via increased feed intake and appropriate feed composition.

a. Increasing feed intake. Increasing feed intake decreases the methane emission per unit of feed intake and decreases the amount of methane per unit of product (Blaxter \& Clapperton 1965; Kirchgessner et al. 1995; Lassey et al. 1997). This is because as intake increases the proportion of methane emission associated with the essential, but nonproductive, requirements for maintenance is diluted.

b. Manipulation offeed composition. Methane is produced in the rumen by the methanogenic Archaea, microbes that utilise carbon dioxide and hydrogen produced by other microorganisms during the fermentation of feed constituents. The individual feed constituents vary in the amounts of carbon dioxide and hydrogen released. Decreasing dietary fibre and increasing starch will reduce methane emission (Blaxter \& Wainman 1964; Moe \& Tyrell 1979). Addition of lipids to the diet can also reduce methane emission (Johnson \& Johnson 1995; Mathison et al.1998). Improving the nutritive value of the feed given to grazing animals by balancing the diet with concentrates, or by breeding improved pasture plants, should result in reduced methane emission. In the grazing ecosystem improvements in intake and feed quality would have to be implemented through improved pasture and animal management, including appropriate supplementation strategies.

\section{Exploiting between-animal variation in methane emission}

A notable feature of methane emission in experiments where large numbers of animals have been fed the same diet, is that there are large differences in emission per unit of feed intake between animals. Between-animal differences account for most the variance, $70-80 \%$, with a lesser amount attributed to differences between measurement days. Such differences between animals 
have been widely observed (Blaxter \& Clapperton 1965; Lassey et al. 1997; Ulyatt et al. 1999) and can persist for some time (Lassey et al. 1997; Pinares-Patiño et al. 2003). We have found that in any group of animals approximately $10 \%$ are high and $10 \%$ low emitters, with the difference between these two groups approximately $40 \%$. The question of whether these differences remain stable over time remains unresolved at present; in one experiment we found that animals selected for differences in emission maintained them for up to four months (Pinares-Patiño et al. 2003). Given that methane results from microbial activity, the animal can only have an impact on this variation through interactions with the microbes directly, either through the diet selected, or indirectly through control of the rumen fermentation environment. Animal effects on fermentation could be via the saliva, feed processing (eg., comminuition), or flow rate through the rumen. It is possible that the animal impact on fermentation is genetically determined and if this is the case it may be possible to obtain markers that can be used to select low methane emitters.

\section{Chemical compounds that reduce methanogenesis}

A wide range of chemicals are available that will reduce rumen methanogenesis (Johnson \& Johnson 1995; Mathison et al. 1998):

(a) Alternative hydrogen acceptors, such as fumarate, sulphate/sulphite, nitrate/nitrite and unsaturated fatty acids. Generally the amount required to be effective in reducing methane emission is likely to be either toxic to the animal, cause disruptions to digestion, or uneconomic.

(b) Halogenated methane analogues, such as, chloroform, carbon tetrachloride, chloral hydrate, bromochloromethane and bromoethanesulphonic acid can be very potent methane inhibitors. While some of these compounds are volatile and difficult to administer, McCrabb et al. (1997) claimed success in inhibiting methane in cattle with bromochloromethane complexed with acyclodextrin, which reduced volatility. Mathison et al. (1998) concluded that halogenated methane analogues have potential as methane inhibitors, provided that problems such as adaptation by rumen microbes, host toxicity and suppression of digestion can be overcome.

(c) Ionophores, such as monensin and lasalocid have been shown to reduce methane emission (Johnson \& Johnson 1995), though in some experiments the affect appears to be short-lived as the rumen microbes adapt to the additive.

(d) Defaunating agents, like manoxol, teric, alkanate 3SL3 and sulphosuccinate can reduce methane emission (Mathison et al. 1998). They appear to act by disrupting the close symbiotic relationship between methanogens and protozoa. Many of these defaunating agents are toxic to the host animal and this restricts their routine use.

(e) Naturally occurring compounds. Some forages contain compounds that appear to have antimethanogenic properties. Gupta et al. (1993) claimed that the leaves of the tropical plant Enterolobium timbouva defaunated the rumen of buffalo, while Woodward et al. (2001) have reported reduced methane emission by feeding sheep the condensed tannin-containing legume Lotus corniculatus. Similarly, Waghorn \& Tavendale (pers. comm.) have shown a $16 \%$ depression in methane by feeding tannincontaining legumes. Ulyatt et al. (2002) found that as yet unknown compounds associated with Kikuyu grass (Pennisetum clandestinum) caused methane depression in grazing sheep and cattle under certain conditions. Such findings offer the prospect of methane reduction in the grazing environment, but a great deal of research is required to identify the compounds concerned and to modify such plants to the stage that they can compete agronomically in the New Zealand grazing environment.

The main problems with chemical additives are that many are toxic to the animal, toxic to rumen microflora and therefore reduce digestion and food intake, have short lived effects because the rumen microbes adapt, are volatile and thus difficult to administer, are expensive, or would fail to meet consumer product acceptance. With grazing animals, especially under extensive conditions, slow release devices would be required to ensure regular delivery into the rumen.

\section{Immunisation}

Scientists in Australia have registered patents for immunisation procedures that are claimed to reduce methane emission. They have developed a vaccine containing an antigen derived from methanogenic microbes (Baker 1998) and an immunogenic preparation which reduces the activity of rumen protozoa (Baker et al. 1997). The antimethanogenic vaccine is claimed to reduce methane in in vitro incubations, and significantly increase feed intake and wool growth. Such vaccines have the potential to provide a cost-effective treatment to reduce methane emission and enhance animal production.

\section{Manipulation of the rumen microbial ecosystem}

The methanogenic Archaea, which are highly efficient 
scavengers of hydrogen, are the main, but not the only, agents that utilise hydrogen in the rumen (Joblin 1999). There is also evidence that the rumen can function satisfactorily in the absence of methanogens (Joblin 1999). There are many potential opportunities for mitigating methane through microbial intervention in the rumen such as: targeting methanogens with antibiotics, bacteriocins, or phage; removing protozoa from the rumen; development of alternative sinks for hydrogen such as reductive acetogenesis (Joblin 1999).

There is a class of bacteria present in the rumen, the acetogens, that utilise carbon dioxide and hydrogen to produce acetic acid, a major nutrient of the ruminant. Acetogens do not compete well in the rumen compared to methanogens, so experiments are in progress to see if the microbial ecosystem can be manipulated to enhance acetogen activity (Joblin 1999). One possible strategy is to genetically modify acetogens so that they can compete more effectively in the rumen.

All these opportunities are possible through microbial intervention, however it is very early days in the research and it may be 20 years before some of these possibilities are realised.

\section{Conclusions}

While at first sight the imposition of levies on production by the government to increase the research effort on methane mitigation may seem a penalty, it should in fact be regarded as an investment by the agricultural industry. Reduction in methane will not only have global environmental benefits, but also, as methane represents a loss of about $6 \%$ of an animal's energy intake, any reduction should be reflected in increased animal productivity per unit of intake. There is also the possibility of developing valuable intellectual property and resultant products. It should be possible to deliver a win/win situation with respect to methane reduction and increased productivity.

\section{REFERENCES}

Baker, S. K. 1998. Method for improving utilisation nutrients by ruminants or ruminant-like animals. Patent Application. International publication number WO 95/11041.

Baker, S. K.; Gnanasampanthan,G.; Purser, D. B.; Hoskinson, R. M. 1997. Immunogenic preparation and method for improving the productivity of ruminant animals. Patent Application. International publication number WO 97/00086.

Blaxter, KL.; Clapperton, J. L. 1965. Prediction of the amount of methane produced by ruminants. British Journal of Nutrition 19: 511-522.

Blaxter, K. L.; Wainman, F. W. 1964. The utilization of the energy of different rations by sheep and cattle for maintenance and for fattening. Jounal of Agricultural Science, Cambridge 63: 113-128.

Clark, H. 2001. Ruminant methane emissions: a review of the methodology used for national inventory estimations. A report prepared for the Ministry of Agriculture and Fisheries by AgResearch.

Gupta, R.; Chaudhary, U. B.; Chauhan, T. R. 1993. Effect of protein supplementation and defaunation on the growth rate of young buffalo heifers. Indian Journal of Animal Sciences 63:179-183.

IPCC. 2001. Climate Change 2001: The Scientific Basis. Contribution of Working Group I to the Third Assessment Report of the Intergovernmental Panel on Climate Change. Pp. 881. Eds. Houghton, J. T.; Ding, Y.; Griggs, D. J.; Noguer, M.; van der Linden, P. J.; Dai, X.; Maskell, K.; Johnson, C. A. United Kingdom, Cambridge University Press.

Joblin, K. N. 1999. Rumen acetogens and their potential to lower ruminant methane emissions. Australian Journal of Agricultural Research 50: 1307-1313.

Johnson, K. A.; Johnson, D. E. 1995. Methane emissions from cattle. Journal of Animal Science 73: 2483-2492.

Kirchgessner, M.; Windisch, W; Muller, H. L. 1995. Nutritional factors for the quantification of methane production. Pp. 333-348. In: Ruminant Physiology: Digestion, Metabolism, Growth and Reproduction. Eds. Engelhardt, W. v.; Leonhard-Marek, S.; Breves, G.; Gieseke, D. Stuttgart, Ferdinand Enke Verlag.

Lassey, K. R.; Ulyatt, M. J.; Martin, R. J.; Walker, C. F.; Shelton, I. D. 1997. Methane emissions measured directly from grazing livestock in New Zealand. Atmospheric Environment 31: 2905-2914.

McCrabb, G. J.; Berger, K. T.; Magner, T.; May, C.; Hunter, R. A. 1997. Inhibiting methane production in Brahmin cattle by dietary supplementation with a novel compound and the effects on growth. Australian Journal of Agricultural Research 48: 323329.

Mathison, G. W.; Okine, E. K.; McAllister, T. A.; Dong, Y.; Galbraith, J.; Dmytruk, O. I. N. 1998. Reducing methane emission from ruminant animals. Journal of Applied Animal Research 14: 1-28.

Moe, P. W.; Tyrell, H. F. 1979. Methane production in dairy cows. Journal of Dairy Science 62: 1583-1586. New Zealand Climate Change Project. 2002. National Inventory Report, New Zealand greenhouse gas inventory 1990-2000. (http://www.climatechange.govt.nz)

Pinares-Patiño, C. S.; Ulyatt, M. J.; Lassey, K. R.; Barry, T. N.; Holmes, C. W. 2003. Persistence of the betweensheep variation in methane emission. Journal of Agricultural Science, Cambridge: In press.

Ulyatt, M. J.; Betteridge, K.; Costall, D.; Knapp, J; Baldwin, R. L. 1991. Methane production by New 
Zealand ruminants. Pp. 27. A report prepared for the Ministry for the Environment, Wellington.

Ulyatt, M. J.; Baker, S. K.; Mc Crabb, G. J.; Lassey, K. R. 1999. Accuracy of $\mathrm{SF}_{6}$ tracer technology and alternatives for field measurement. Australian Journal of Agricultural Research 50: 1329-1334.

Ulyatt, M. J.; Lassey, K. R.; Shelton, I. D.; Walker, C. F. 2002. Methane emission from dairy cows and wether sheep fed sub-tropical grass-dominant pastures in mid summer in New Zealand. New Zealand Journal of Agricultural Research: In press.

Woodward, S. L.; Waghorn, G. C.; Ulyatt, M. J.; Lassey, K. R. 2001. Early indications that feeding Lotus will reduce methane emissions from ruminants. Proceeding of the New Zealand Society of Animal Production 61: 23-26. 